\title{
Gênero, migração e vulnerabilidade: corpos de mulheres em deslocamento
}

Rita de Cassia Quadros da Rosa', Betina Hillesheim², Douglas Luís Weber³, Leticia Silva Holderbaun ${ }^{4}$

I Mestra em Educação e doutoranda em Educação pela Universidade de Santa Cruz do Sul - UNISC. Lajeado - RS, Brasil. E-mail: ritaquadrosdarosa@hotmail.com

2 Doutora em Psicologia pela Pontifícia Universidade Católica. Porto Alegre - RS. Brasil. Professora do departamento de Psicologia e do Programa de Pós-Graduação em Educação da Universidade de Santa Cruz do Sul - UNISC.

Santa Cruz do Sul - RS, Brasil. E-mail: betinah@unisc.br

3 Mestre em Educação e doutorando em Educação pela Universidade de Santa Cruz do Sul - UNISC. Santa Cruz

do Sul-RS, Brasil. E-mail: douglasluis94@hotmail.com

${ }^{4}$ Graduanda em Psicologia pela Universidade de Santa Cruz do Sul - UNISC. Santa Cruz do Sul - RS, Brasil.

E-mail: leticiaholderbaun@gmail.com

\section{Resumo}

O presente artigo pretende discutir a situação das mulheres no contexto de migração e refúgio, tendo em vista as vulnerabilidades específicas relacionadas a gênero. Para tanto, realizamos uma análise sobre o tema, a partir de documentos produzidos pela International Organization for Migrations - IOM, pelo Alto Comissariado das Nações Unidas para os Refugiados - ACNUR e pela Federação Internacional de Direitos Humanos - FIDH. As discussões tiveram como pressupostos teóricos os Estudos Feministas e de gênero na perspectiva pós-estruturalista. A partir das reflexões foi possível compreender que as mulheres inseridas em fluxos migratórios estão suscetíveis a necessidades específicas dada a sobreposição das categorias "mulher" e "migrante", as quais produzem um quadro de dupla exclusão que costuma condicionar sua vivência desde o Estado de origem. Trata-se de uma característica que diferencia a migração feminina, pois ficam para trás seus pertences, seus bens e suas famílias, mas os fatores de vulnerabilidade acompanham o deslocamento de seus corpos.

Palavras-chave: Migração. Gênero. Mulheres. Vulnerabilidade.

\section{Abstract}

This text aims to discuss the situation of women in the context of migration and refuge, in view of specific vulnerabilities related to gender. For this purpose, we analyze documents by the International Organization for Migration (IOM), the United Nations High Commission for Refugees (UNHCR) and the International Federation of Human Rights (FIDH). The discussions had the theoretical assumptions of Feminist and Gender Studies in the poststructuralist perspective. It was possible to understand that women in migratory flows are susceptible to specific needs given the overlapping of the categories "woman" and "migrant", which produce a double exclusionary framework that usually conditions their experience from the State of origin. This is a characteristic that differentiates female migration, because they keep their belongings, their assets and their families behind, but the factors of vulnerability accompany the displacement of their bodies.

Key-Words: Migration. Gender. Women. Vulnerability. 


\section{Introdução}

Nos últimos anos, os fluxos migratórios têm alcançado números sem precedentes, acarretando a necessidade de ampliação dos estudos sobre o tema. Mirjana Morokvasic, segundo Assis e Kosminsky (2007), sugere que as mulheres têm sido tradicionalmente negligenciadas nas pesquisas sobre migração, sendo que as especificidades deste segmento de migrantes e as relações de gênero foram pouco problematizadas nessas produções. As autoras apontam que "até recentemente, a migração internacional era majoritariamente tratada como um fenômeno que envolvia particularmente os homens" (p. 695). Embora frequentemente fosse contabilizado o contingente de mulheres que participaram dos fluxos migratórios, a invisibilidade das questões de gênero prevalecia. Em pesquisas recentes, têm-se discutido a respeito das particularidades femininas implicadas no processo de migração.

Embora as razões político-econômicas da migração tenham sido amplamente exploradas pelas teorias sobre migração, as mesmas têm negligenciado, entretanto, as vulnerabilidades que frequentemente levam a população feminina a se deslocar. Os fatores que levam homens e mulheres a migrar, assinala Lisboa (2006), são distintos. A partir da constatação de que as experiências de migração distinguem-se com base no gênero, cabe nos perguntarmos o que sustentaria essa diferença.

Lisboa (2006) aponta para um processo de "feminização da migração", atrelado ao fenômeno da "feminização na pobreza" - segundo dados da ONU, $70 \%$ da população pobre do mundo é composta por mulheres. Por esta razão, as mulheres têm crescentemente migrado de forma autônoma. Estes fluxos têm se caracterizado tanto por deslocamentos internos quanto externos. O caráter autônomo da migração feminina vai de encontro a uma visão frequentemente reproduzida em pesquisas sobre essa temática, que assumem as mulheres como sujeitos passivos dos deslocamentos internacionais (ASSIS; KOSMINSKY, 2007).

A partir disso, o presente artigo pretende discutir a situação das mulheres no contexto de migração e refúgio, tendo em vista as vulnerabilidades específicas relacionadas a gênero. Para tanto, realizamos uma análise sobre o tema, a partir de documentos produzidos pela International Organization for Migrations - IOM, pelo Alto Comissariado das Nações Unidas para os Refugiados - ACNUR e pela Federação Internacional de Direitos Humanos - FIDH. Para dar conta da discussão aqui proposta, o texto está organizado da seguinte maneira: em um primeiro momento, trazemos uma revisão teórica que abrange uma discussão sobre o conceito de gênero a partir dos Estudos Feministas e de gênero pós-estruturalistas, bem como as questões específicas atinentes às mulheres inseridas nos fluxos migratórios, discorrendo sobre as questões relativas à migração e refúgio e as situações de desigualdade vivenciadas pelas mulheres. Compreende-se que, como argumenta Butler (2003), se o gênero é produzido como efeito de diversas instâncias sociais, ele constitui, em contrapartida, experiências profundamente generificadas, produzindo situações de desigualdade entre homens e mulheres. Após, discorremos brevemente sobre a metodologia utilizada para a realização da pesquisa, apresentando, a seguir, a análise dos documentos. Para finalizar, teceremos algumas considerações acerca dos documentos analisados.

\section{Gênero e desigualdade entre mulheres e homens}

Considerando-se as teorizações da filósofa estadunidense Judith Butler na sua obra Problemas de gênero, originalmente publicada em 1990, pode-se afirmar que aquilo que reconhecemos socialmente como "muIher" não o tem sido sempre. Os sujeitos de gênero são historicamente e socialmente produzidos mediante relações de poder e discursos que favorecem o seu aparecimento histórico. As categorias binárias de gênero - homem e mulher -, as quais organizam largamente a experiência social humana, são fruto de uma produção de sujeitos em que os corpos assumem significados generificados, por meio de práticas e discursos que reiteram e reafirmam, repetidamente, as categorias de gênero que funcionam em determinado contexto histórico e social (BUTLER, 2003).

A experiência social da diferença binária entre os gêneros sustenta e, ao mesmo tempo, é sustentada por um modelo de diferenciação sexual igualmente binário, de modo que se espera que haja uma convergência entre os atributos anatômicos designados como um gênero em particular e a identificação pessoal de um indivíduo com o gênero que supostamente seria correspondente a esta configuração física (BUTLER, 2003). Esta concepção pode ser traçada historicamente e localizada na instauração de um modelo particular de 
diferença sexual, conforme aponta o sociólogo francês Michel Bozon (2004), a qual remonta ao século XIX, tendo sido responsável por atribuir aos corpos masculinos e femininos uma relação de oposição, de modo que estes passaram a ser considerados fundamentalmente distintos. Embora anteriormente já se verificasse a existência de papeis sociais distintos ocupados por homens e mulheres, a diferenciação sexual que se supunha antes da concepção binária era dada em graus.

É possível localizar na Antiguidade, portanto, a existência de uma experiência social generificada, a qual já concebia o papel social masculino e o feminino, ainda que a diferença sexual fosse assumida como gradativa em uma escala na qual todos eram concebidos como homens, variantes apenas quanto ao seu nível de perfeição, como aponta o historiador americano Thomas Laqueur (ROHDEN, 1998).

Tendo isso em vista, é possível compreender o argumento exposto por Butler (2003) a respeito das origens desta forma particular de experiência generificada. Produzido a partir de "instituições, práticas e discursos cujos pontos de origem são múltiplos e difusos" (p. 9), o gênero, em vez de encontrar sua origem na existência supostamente fixa e pré-discursiva de um sexo biológico, informa, ele mesmo, as formas de conceber e classificar os corpos.

É importante ressaltar, entretanto, que a maleabilidade das categorias de gênero não significa que essas não produzam efeitos reais na sociabilidade dos corpos demarcados pelo gênero masculino ou feminino. Dessa forma, materializando-se discursivamente nos corpos através de práticas reiterativas, o gênero torna-se impregnado nas relações sociais, de modo que estas, além de produzirem a experiência generificada, manifestam-se em consonância com as condições que possibilitam a existência de sujeitos de gênero (BUTLER, 1993).

Sendo assim, desigualdades de gênero podem se manifestar em diferentes âmbitos, ainda que constitucionalmente o status da mulher se iguale ao do homem na maioria dos países'. Costa e Schwinn (2018), ao discorrerem sobre o estatuto jurídico das mulheres, afirmam que o progresso das leis que intencionam assegurar a igualdade de direitos entre os gêneros não garante a concretização desse objetivo. Embora constituam um importante instrumento, capaz de fomentar transformações sociais e a adoção de políticas favoráveis às mulheres, as leis que servem de referência para a igualdade entre os gêneros são insuficientes para romper com normas sociais desiguais. A concretização de direitos está sujeita a "condições políticas, econômicas e sociais mais amplas que moldam os meios de subsistência e as relações sociais" (COSTA; SCHWINN, 20I8, p. 123).

O Relatório "Progress of the World's Women 2015-2016: Transforming Economies", produto de uma investigação empreendida pela ONU Mulheres, aponta uma série de desvantagens econômicas e laborais que acometem as mulheres globalmente. De acordo com dados deste relatório, o nível de desemprego entre as mulheres é maior do que entre homens, ao passo que, quando inseridas nas atividades laborais, as mulheres tendem a receber menos do que os homens para a execução das mesmas atividades. Ademais, as mulheres compõem um contingente menor entre os trabalhadores, sendo que apenas metade da população feminina em idade ativa está inserida na força de trabalho global, em comparação à participação laboral de três quartos dos homens com I5 ou mais anos de idade (UN WOMEN, 20I5; COSTA; SCHWINN, 20I8).

Embora a força de trabalho mundial seja majoritariamente composta por homens, o relatório supracitado salienta que as mulheres são desproporcionalmente responsáveis por atividades domésticas e não remuneradas. Somado a isso, a população feminina está distintamente desamparada no que tange à garantia de direitos, tendo em vista que o trabalho exercido por mulheres está inserido na economia informal, sem estar contemplado por leis trabalhistas (UN WOMEN, 20I5; COSTA, SCHWINN, 20I8).

A partir de tais considerações, é possível verificar que, como discute Scott (2007), a construção social do gênero está relacionada a relações de poder entre homens e mulheres, as quais operam tanto nos níveis materiais, quanto nos níveis simbólicos da realidade. Nessa perspectiva, podemos compreender que, nas situações de migrações, os quadros de desigualdade que atingem as mulheres acarretam determinadas condições de vulnerabilidade, conforme desenvolvido a seguir.

\footnotetext{
' Dados da UN Women indicam que, em 2014, I43 do total de 195 países garantiam, em suas constituições, igualdade entre homens
} e mulheres. Disponível em: http://www.unwomen.org/en/digital-library/multimedia/2015//2/infographic-human-rights-women. 


\section{As Mulheres e os Fluxos Migratórios}

Ao longo da história, os processos migratórios estiveram relacionados à constituição das dinâmicas sociais que permeiam a vida humana. Segundo a International Organization for Migrations - IOM a migração é o

processo de atravessamento de uma fronteira internacional ou de um Estado. É um movimento populacional que compreende qualquer deslocação de pessoas, independentemente da extensão, da composição ou das causas; inclui a migração de refugiados, pessoas deslocadas, pessoas desenraizadas e migrantes econômicos (p. 40, 2009).

Ainda, esse órgão intergovernamental entende que a migração beneficia o migrante e a sociedade, uma vez que busca fomentar o desenvolvimento humano, social e econômico que, por conseguinte, dignifica a escolha e o direito humano básico de trânsito por qualquer espaço ou local (IOM, 2009).

Weintraub, Tittanegro e Vasconcellos (2014) afirmam que existem duas formas de migração: as migrações nacionais/internas e as migrações internacionais. As migrações nacionais/internas são a circulação de pessoas de uma região do país para outra, com a finalidade ou o efeito de fixar nova residência. Este tipo de migração pode ser temporária ou permanente. $O$ migrante interno desloca-se, mas permanece dentro do seu país de origem (por ex., migração de zonas rurais para zonas urbanas). Por outro lado, as migrações internacionais, que são o foco desse trabalho, são entendidas como movimentos de pessoas que deixam os seus países de origem ou de residência habitual para se fixarem, permanente ou temporariamente, noutro país. Consequentemente, pressupõem a transposição de fronteiras internacionais.

Segundo os autores acima citados, as características culturais identitárias acabam por implicar em novos e diversos modos de compreensão do mundo, assim como diferentes acontecimentos e motivos passam a organizar diversos níveis de deslocamento. Dessa forma, emergem variadas categorias de migração, as quais buscam exemplificar as singularidades desses processos, como, por exemplo, migrações pendulares, forçadas, espontâneas, ilegais, laborais, ordenadas, secundárias, o refúgio, entre outras (WEBER, 2017).

Ressalta-se ainda que as maiores facilidades de transporte encurtaram as distâncias entre diversos espaços que, anteriormente, encontravam-se, muitas vezes, isolados, abrindo o fluxo de movimento entre os países. Segundo Weber (2017), os motivos que atualmente levam as populações a migrarem passam, principalmente, pela busca por qualidade de vida, a qual abrange vários elementos, destacando-se: melhores oportunidades de emprego e recursos de cunho econômico, melhor acesso e condições de educação, saúde de qualidade, segurança pública, saneamento básico, entre outros.

Entretanto, é importante apontar que nem todos os tipos de migrações acontecem a partir da vontade do migrante: as chamadas migrações forçadas se configuram no deslocamento obrigatório das populações por motivos de guerras, perseguições étnicas, políticas ou religiosas, desastres naturais, etc. (IOM, 2009).

Tais acontecimentos, principalmente nas últimas décadas, passaram a aumentar drasticamente o número de pedidos de refúgio. Segundo a IOM (2009), o refúgio engloba todos os migrantes que estão fora de seu país de origem devido a fundados temores de perseguição relacionados a questões de raça, religião, nacionalidade, pertencimento a um determinado grupo social ou opinião política, como também devido à grave e generalizada violação de direitos humanos e conflitos armados.

Sendo assim, nossas discussões se centrarão nas distintas necessidades, opressões e violências sofridas por mulheres inseridas em fluxos migratórios, sem que nos fixemos em diferenciar o status político como migrante ou refugiado. Nesse sentido, apontamos que as dificuldades do processo migratório se somam às desigualdades de gênero, acentuando-se as vulnerabilidades vivenciadas por mulheres. Costa e Schwinn (2018) assinalam que mulheres em situação de migração tendem a receber remuneração inferior à dos homens migrantes por suas atividades laborais, ainda que uma razão frequente para a migração feminina seja a busca por melhores condições de vida. Além disso, mulheres estão mais suscetíveis a sofrerem situações de violência no contexto migratório, ao passo que a própria violência - na sua especificidade de gênero - tem sido destacada como propulsora da participação de mulheres nos deslocamentos internacionais, bem como a fuga de contextos discriminatórios e de normas sociais repressoras.

Meninas e mulheres são desproporcionalmente atingidas pela violação de direitos humanos na trajetória de migração, destacando-se a ocorrência de abusos como "violência sexual, tráfico de mulheres, escravidão em locais de trabalho, impossibilidade de contato com a família" (SCHWINN; COSTA, 2016, p. 225).

Rosa et al. | Rev. Elet. Cient. da UERGS (2019) v. 5, n. especial, p. I38-146 
Assim, a vitimização anterior ao deslocamento se estende durante o processo migratório e perdura após o estabelecimento em uma sociedade de destino, de modo que diferentes tipos de violência se reproduzem nesses contextos de acordo com o estágio da situação migratória. Ofelia Woo Morales, citada por Schwinn e Costa (20l6), expõe tipos de violência enfrentada por mulheres e meninas em situação de migração, sendo que algumas destas formas de violência ocorrem em razão do gênero, as quais podem se manifestar como violência psicológica ou sexual. A primeira delas caracteriza-se pela opressão e perseguição na sociedade de origem, sendo agravada pela condição de refugiada. A segunda, por sua vez, envolve práticas como "o uso do estupro como arma de guerra; a exploração sexual e o tráfico a mulheres e meninas para fins sexuais; 0 assédio no local de trabalho" (SCHWINN; COSTA, 2016, p. 226).

\section{Procedimentos Investigativos}

Este artigo consiste em uma pesquisa bibliográfica que expõe as vulnerabilidades às quais as mulheres migrantes estão submetidas em razão de seu gênero. Para tanto, utilizamos como materialidade de estudo os documentos produzidos pela International Organization for Migrations - IOM, pelo Alto Comissariado das Nações Unidas para os Refugiados - ACNUR e pela Federação Internacional de Direitos Humanos - FIDH. Especificamente, os documentos analisados são os que se seguem: (I) Global Migration Indicators (IOM, 20 I8); (2) Initial Assessment Report: Protection Risks for Women and Girls in the European Refugee and Migrant Crisis (UNHCR, 20I6); e (3) Women and Migration, relatório resultante do Forum on Migration - Regional \& Thematic Papers (FIDH, 2007).

Buscamos problematizar, a partir de dados apresentados nestes documentos, os fatores de vulnerabilidade específicos ao gênero feminino que levam as mulheres a cruzar as fronteiras internacionais, bem como as dificuldades e os eventuais abusos sofridos no processo migratório que afetam as mulheres desproporcionalmente. Além disso, as desigualdades enfrentadas por mulheres nos países de destino foram consideradas em sua especificidade de gênero. A fim de substanciar a discussão teoricamente, adotamos como pressuposto uma perspectiva que considera os efeitos das materializações de gênero como geradores das desigualdades sociais entre homens e mulheres, expostos na linha pós-estruturalista pela filósofa estadunidense Judith Butler.

Sob esta perspectiva, analisamos dados dos documentos referentes ( $I$ ) à inserção das mulheres migrantes no mercado de trabalho, atentando para as diferenças salariais em relação aos homens e para as responsabilidades atribuídas desproporcionalmente às mulheres; e (2) à violência contra as mulheres no contexto da migração e do refúgio, manifestada frequentemente na forma de violência sexual.

\section{Vulnerabilidade Feminina e Migração}

Cruz e Hillesheim (2013) marcam que o conceito de vulnerabilidade foi incorporado ao campo da saúde a partir dos anos de 1980, com os estudos sobre HIV/AIDS, sendo que há uma vinculação estreita com a ideia de risco, sendo muitas vezes utilizados como sinônimos, apesar de darem conta de questões distintas. Citando Nichiata et al. (2008), as autoras colocam que enquanto

[...] nos estudos epidemiológicos, o risco é um conceito bastante sólido, com um caráter analítico, que busca estabelecer associações entre eventos ou condições e controlar os graus de incerteza, (...) a vulnerabilidade é um conceito emergente, com um caráter mais voltado para uma síntese, isto é, estabelece uma elaboração mais concreta e particularizada no que se refere às articulações entre os fenômenos associados à condição de vulnerabilidade. (CRUZ; HILLESHEIM, 20I3, p. 300-30I).

Além disso, as autoras enfatizam, a partir de Ayres (200I), que o conceito de vulnerabilidade pretende superar o foco no indivíduo e os aspectos probabilísticos que estão implicados na noção de risco, problematizando os elementos coletivos e as condições de suscetibilidades aos agravos.

Tendo em vista, portanto, que vulnerabilidade não é um conceito que se aplica ao indivíduo, mas diz respeito a determinadas condições que trazem uma certa desvantagem social, é possível perceber, nos diferentes documentos, o quanto as mulheres, como grupo, estão colocadas em situações de maior vulnerabilidade. 
De acordo com o Global Migration Indicators (IOM, 20I8), no ano de 2017 havia um total de 258 milhões de pessoas residindo em países que não eram seu país de nascimento. Destas, aproximadamente 48 por cento eram mulheres que deixaram seus países de origem de forma deliberada, em busca de melhores condições de vida ou por deslocamento forçado. Além das razões que costumam motivar o deslocamento de pessoas pelo mundo, as mulheres fazem parte de um grupo vulnerável a circunstâncias específicas de opressão, perseguição e violência por questões de gênero.

No que se refere ao local de origem, há situações de violência e opressão vinculadas a aspectos culturais e/ou religiosos - fatores de repulsão - que incidem especificamente sobre as mulheres, motivando sua partida. Além disso, as questões econômicas em um cenário de feminização da pobreza, impõem a busca por alternativas que ofereçam melhores condições de existência para si e para suas famílias (LISBOA, 2006). Considerando que atualmente as mulheres representam $70 \%$ do total de pessoas ocupando a faixa de pobreza no mundo, entende-se o aumento considerável do número de mulheres migrantes nas últimas décadas (ONU, 2016).

Se o Estado de origem se torna hostil à sobrevivência de mulheres fazendo com que partam, os locais de trânsito e destino nem sempre oferecem melhores condições. A sobreposição das categorias "mulher" e "migrante" produz uma dupla exclusão que acaba condicionando sua vivência em um cenário de vulnerabilidade, pois são vítimas das mesmas desigualdades e discriminações que incidem sobre as mulheres locais, somadas às opressões por ocupar a condição de sujeito migrante. Embora fuja do escopo desse trabalho, não podemos deixar de mencionar que parte dessas mulheres estão incluídas também em outros grupos identitários afetados por preconceito de classe, religioso, racial, identidade de gênero e/ou sexualidade.

A violência contra as mulheres configura-se como uma das mais evidentes manifestações da desigualdade de gênero. De acordo com o estudo realizado pela ONU através da ACNUR, Initial Assessment Report: Protection Risks for Women and Girls in the European Refugee and Migrant Crisis (UNHCR, 2016), o risco de violência, extorsão, exploração, tráfico de seres humanos e órgãos, é constante para mulheres e homens. No entanto, são as mulheres as mais vulneráveis, sendo, com frequência, alvo de violência sexual impetrada pelos próprios atravessadores durante os percursos migratórios ou no Estado de destino, em troca de alimento e abrigo. De acordo com o estudo, meninas e adolescentes também são alvo de violência sexual e tráfico de pessoas para trabalhos forçados, incluindo escravização sexual.

Embora a ONU, na última década, venha se mostrando atenta às questões específicas das mulheres migrantes, a busca por soluções junto a autoridades governamentais e humanitárias esbarra nos mesmos entraves conhecidos historicamente no que tange à violência contra as mulheres de uma forma geral. De acordo com o relatório, em virtude da escassez de dados concretos sobre onde, quem e como este tipo de violência é praticado, não há como atuar para combatê-lo (UNHCR, 20I6).

Para as pesquisadoras Narvaz e Koller (2006), este tipo de silenciamento e invisibilidade, que acomete as vítimas de abusos, é resultado dos jogos de poder que mantém as hierarquias entre mulheres e homens. De acordo com as autoras, existem inúmeros processos que podem fazer com que mulheres silenciem sobre situações de violência e abuso.

Vivências de violência na família de origem; a re-vivência do abuso sexual sofrido em sua infância e a falta de modelos de família protetiva; as estratégias de culpabilização das vítimas, acusadas de sedutoras pelo perpetrador do abuso; o desejo de ter uma família e de manter a família unida; a dependência emocional e econômica dos parceiros abusivos; o medo do companheiro abusivo, que era violento fisicamente e fazia uso de álcool; a prescrição de obediência e submissão engendrada pelo poder patriarcal; e, a falta de apoio familiar, comunitário e/ou social (NARVAZ; KOLLER, 2006, p. 10).

Tais circunstâncias incidem sobre as mulheres de uma maneira geral. Acrescenta-se a essas, toda a carga que se impõe sobre os sujeitos migrantes, tal como o receio de não encontrar trabalho, de não obter sustento para si e para a família, de ter sua permanência negada, as dificuldades de encontrar redes de apoio em virtude do idioma e outros entraves. Assim, a menos que haja implicações graves e risco de morte após abuso e violência, as mulheres migrantes e refugiadas não procuram autoridades para informar os casos, fortalecendo a percepção de que este é um "problema menor", conforme aponta também o estudo da ONU. 
Nenhuma iniciativa liderada por agências governamentais, com o objetivo de conhecer os riscos relacionados à violência sexual contra mulheres, ficou evidente durante a missão. Apesar da pesquisa existente e do progresso feito no trabalho contra este tipo de violência, ainda existe uma percepção entre muitas das autoridades governamentais e agentes humanitários entrevistados de que a abuso e violência sexual contra mulheres migrantes e refugiadas, não é uma característica importante desta crise² (EAPEAN, 2016, p. 7).

O excerto acima apresenta uma das conclusões obtidas pelos pesquisadores acerca da maneira como (não) são tratadas as questões de gênero. A abordagem dos órgãos encarregados da assistência aos migrantes e refugiados trata esse contingente de pessoas como uma massa homogênea, ou seja, masculina, heterossexual e em idade adulta. Assim, mesmo estando a par de que aproximadamente metade dessas pessoas são mulheres, com vulnerabilidades específicas, o tratamento é dado indistintamente.

Ao dar tratamento igual aos diferentes, desconsiderando suas necessidades, perpetuam-se situações de opressão, abuso e violência sobre os grupos desfavorecidos, no caso, as mulheres. Por essa razão, não se pode dizer que não há responsabilidade dos órgãos e autoridades envolvidos nos fluxos migratórios para com as inúmeras formas de violência impetradas contra as mulheres; ao contrário, é preciso considerar que sua omissão tem efeitos ativos na cristalização deste cenário.

Foi identificado também a existência de uma modalidade de abuso sexual que se mescla com extorsão, denominada pelas autoridades como "sexo transacional"3 (EAPEAN, 2016, p. 7). Esse abuso atinge mulheres inseridas em fluxos migratórios e consiste em coagi-las, normalmente durante a travessia, quando não há como desistir, a fazer sexo em troca de documentos obrigatórios, tais como passaporte ou bilhetes para acessar outros meios de transporte que sejam imprescindíveis para o sucesso do deslocamento. Trata-se de um tipo de violência em que o corpo das mulheres, às vezes ainda crianças, são tomados como mero objeto de troca.

Olhar para os casos de violência e abuso sexual sofrido pelas mulheres migrantes e refugiadas, requer que consideremos a relação que as sociedades inseridas nos fluxos migratórios possuem com o corpo feminino. Abrimos aqui um parêntese para discutir os efeitos dos discursos que historicamente produzem a masculinidade e feminilidade hegemônicas. De acordo com Machado (1998), é importante compreender que a noção de masculinidade produzida culturalmente, está pautada por uma ideia de virilidade que precisa se apoderar unilateralmente do corpo da mulher para obter legitimidade. $O$ fato de as mulheres serem tomadas como sujeitos passivos em face à relação sexual, sempre à espera da iniciativa dos homens, produz condições para que abusadores diminuam a gravidade de seus crimes ou argumentem terem confundido os limites do que é consensual.

Neste sentido, as características atribuídas ao gênero feminino, que lhe conferem fragilidade, sensibilidade, passividade e maternalidade, contrastam com aquelas atribuídas ao masculino como forte, racional, ativo e protetor, nos termos da complementaridade sexual e da manutenção da matriz heterossexual (BUTLER, 2003). Normas de comportamento e recato ressonantes dos discursos médico e religioso, desencorajam a manifestação do desejo feminino, mas constituem como imprescindível a manifestação do desejo masculino. Assim, o que se produz em termos de atributos de gênero, além de se limitar ao binário excludente feminino/ masculino, atua na formação de uma cultura que incide sobre os corpos femininos - ou "afeminados" - tomando-os como objeto, no interior e para além das situações de migração e refúgio.

No que se refere à inserção no mundo do trabalho, seja formal ou informalmente, de acordo com o Global Migration Indicators (IOM, 20I8) - números baseados no ano de 2013 - estima-se que 45 por cento dos migrantes trabalhadores sejam mulheres. Embora não encontrem dificuldades significativas em relação aos homens para se inserir em vagas de trabalho, os postos ocupados por mulheres costumam ser pior remunerados. O relatório da Organização não Governamental - ONG internacional Mouvement Mondial des Droits Humains, aponta que no ano de 2007 as mulheres migrantes e refugiadas se restringiam a desempenhar funções ditas femininas, tais como: diarista, camareira, babá, cozinheira, cuidadora, servente de limpeza. No contexto de sociedades fundadas sobre valores masculinos, tais ocupações dispõem de retribuição financeira inferior, o que mantém as mulheres em situação de subordinação em virtude do gênero. No entanto,

\footnotetext{
${ }^{2} \mathrm{~A}$ comprehensive and survivor-centred approach led by government agencies, aimed at addressing SGBV-related protection risks, was not evident during the mission. Notwithstanding the existing research and progress made in the work against SGBV, there is still a perception among many of the government authorities and humanitarian actors interviewed that SGBV is not a major feature of this crisis. Tradução dos autores.

${ }^{3}$ Transactional sex. Tradução dos autores.
} 
de acordo com o relatório, embora recebam salários inferiores, as mulheres são responsáveis pela maior remessa de dinheiro aos familiares que permanecem nos países de origem. Dessa maneira, as mulheres compensam os menores salários remetendo uma porção maior de sua renda, o que dificulta sua ascensão financeira no país de destino (FIDH, 2007).

Estes dados nos auxiliam a compreender o quanto o objetivo de contribuir para o sustento das famílias é determinante para as mulheres ao decidirem migrar. Além disso, nos permitem olhar para a importância que conferem ao sentido de família, carregando-as consigo, ainda que impedidas de estarem juntas. De acordo com a pesquisadora Scavone (200I), essa noção de responsabilidade pode ser compreendida como parte das produções acerca da mulher como sujeito que não apenas precisa ser a base de sustentação da família, como tem nela e na maternidade sua única possibilidade de completude, ainda que isso acarrete na manutenção de sua subordinação social e econômica.

A partir do que foi apresentado a respeito das vivências, necessidades e vulnerabilidades das mulheres migrantes e refugiadas, nos foi possível tecer algumas considerações, as quais se seguem.

\section{Considerações Finais}

As mulheres inseridas em fluxos migratórios estão suscetíveis a necessidades específicas dada a sobreposição das categorias "mulher" e "migrante", as quais produzem um quadro de dupla exclusão que costuma condicionar sua vivência desde o Estado de origem. A exposição a situações de violência e abuso sexual, que, em muitos casos, é fator de repulsão, não cessa ao longo do percurso migratório. Trata-se de uma característica que diferencia a migração feminina, pois os riscos de violência acompanham o deslocamento de seus corpos.

Sendo o gênero um fator de vulnerabilidade para mulheres migrantes e refugiadas, se fazem necessárias políticas de proteção a esses sujeitos, as quais tenham como prioridade a produção de dados específicos sobre suas necessidades. A ausência de notificação dos casos de violência e a ausência de políticas protetivas em virtude da ausência de notificações, consiste em um paradoxo imobilizante. No entanto, uma vez que se tenha conhecimento sobre a ocorrência de violências, ainda que não de maneira formal - conforme apresentamos ao longo desse trabalho - pode-se conceber a atitude pouco propositiva dos órgãos governamentais e humanitários em oferecer proteção como um posicionamento ativo na manutenção das mulheres migrantes e refugiadas em posição de vulnerabilidade.

Assim como a exposição a situações de violência, a dificuldade em romper com os limites impostos pelas normas de gênero na ocupação de vagas de trabalho, restringido seu acesso às profissões ditas femininas, contribui para perpetuar desigualdades. Alia-se a isso o fato de as mulheres estarem propensas a assumir a responsabilidade pelo sustento das famílias que permanecem nos Estados de origem, dividindo com elas uma parte considerável do que recebem por suas atividades laborais.

Para finalizar estas considerações, salientamos que se tratam de apontamentos iniciais e afirmamos a necessidade de aprofundarmos estas análises a posteriori, alargando a compreensão de gênero para além do binário homens/mulheres descrito neste trabalho, bem como marcadores de raça/etnia, geração, classe, religião e sexualidade.

\section{Referências}

ASSIS, Gláucia de Oliveira; KOSMINSKY, Ethel V. Gênero e migrações contemporâneas. Estudos Feministas, Florianópolis, v. 15, n. 3, p. 695-697, set./dez. 2007. Disponível em: <http://www.scielo.br/pdf/ref/vl5n3/al2vl5n3.pdf>. Acesso em: 07 jan. 2019.

AYRES, José Ricardo de Carvalho Mesquita. Sujeito, intersubjetividade e práticas de saúde. Ciência \& saúde coletiva, Rio de Janeiro, v. 6, n. I, p. 63-72, 2001.

BOZON, Michel. Sociologia da sexualidade. Rio de Janeiro: FGV, 2004.

BUTLER, Judith. Bodies that matter: on the discursive limits of "sex". New York, NY: Routledge, 1993.

Problemas de gênero: Feminismo e subversão da identidade. Rio de Janeiro: Civilização Brasileira, 2003.

COSTA, Marli Marlene Moraes da; SCHWINN, Simone Andrea. Qual o lugar das mulheres no mundo? O peso dos estereótipos de gênero sobre as mulheres migrantes e refugiadas. Revista do Programa de Pós Graduação em 
Direito da UFC, Fortaleza, v. 38, n. 2, 2018, p. I I7-I31. Disponível em: <http://www.periodicos.ufc.br/nomos/article/ view/30859>. Acesso em 05 jan. 2019.

CRUZ, Lilian Rodrigues da; HILLESHEIM, Betina. Vulnerabilidade social. In: Rosa M. C. Fernandes; Aline Hellmann. (Org.). Dicionário Crítico: Política de Assistência Social no Brasil. Porto Alegre: UFRGS, 2016, v. I, p. 300-302. Disponível em: <https://www.ufrgs.br/cegov/files/pub_70.pdf>. Acesso em: 2 jan. 2019.

INTERNATIONAL FEDERATION FOR HUMAN RIGHTS - FIDH. Women and migration. In: FORUM ON MIGRATION - FIDH CONGRESS, 36., 2007. Lisboa. Anais... Lisboa: FIDH, 2007. Não paginado.

LISBOA, Teresa Kleba. Gênero e migrações - trajetórias globais, trajetórias locais de trabalhadoras domésticas. Revista Interdisciplinar de Mobilidade Humana, Brasília, v. 14, n. 26-27, p. 151-166, 2006. Disponível em: <https://www. redalyc.org/pdf/4070/407042004005.pdf >. Acesso em: 08 jan. 2019.

MACHADO, Lia Zanotta. Masculinidade, sexualidade e estupro: as construções da virilidade. Cadernos Pagu, n. II, p. 23I-273, 1998.

NARVAZ, Martha Giudice; KOLLER, Sílvia Helena. Mulheres vítimas de violência doméstica: compreendendo subjetividades assujeitadas. Psico, v. 37, n. I, p. 8, 2006. Disponível em: <https://dialnet.unirioja.es/servlet/articulo?codigo $=5|6| 476>$. Acesso em: 7 jan. 2019.

NICHIATA, Lucia Yasuko Izumi et al. A utilização do conceito "vulnerabilidade" pela enfermagem. Revista Latino Americana de Enfermagem, Ribeirão Preto, v. 16, n. 5, p. 923-928, out. 2008.

ORGANIZAÇÃO INTERNACIONAL DE MIGRAÇÃO - IOM. Glossário sobre migração. 2009. Disponível em: $<$ http://publications.iom.int/system/files/pdf/iml22.pdf>. Acesso em: 07 jan 2019.

ORGANIZAÇÃO DAS NAÇÕES UNIDAS - ONU. Feminização da pobreza. 20I6. Disponível em: < https://nacoesunidas.org/mulheres-sao-principais-beneficiarias-de-politicas-sociais-brasileiras-diz-publicacao-de-agencia-da-onu/>. Acesso em: 07 jan. 2019.

ROHDEN, Fabíola. O corpo fazendo a diferença. Mana, Rio de Janeiro, v. 4, n. 2, p. 127-14I, 1998. Disponível em: <http://www.scielo.br/pdf/mana/v4n2/2415.pdf>. Acesso em: 03 jan. 2019.

SCAVONE, Lucila. A maternidade e o feminismo: diálogo com as ciências sociais. Cad. Pagu, Campinas, n. 16, p. 137-I50, 200I. Disponível em: <http://www.scielo.br/scielo.php?script=sci_arttext\&pid=S0 I04-8333200 I000 I0000 8\&lng=en\&nrm=iso >. Acesso em: 09 Jan. 2019.

SCHWINN, Simone Andrea; COSTA, Marli Marlene Moraes da. Mulheres refugiadas e vulnerabilidade: a dimensão da violência de gênero em situações de refúgio e as estratégias do ACNUR no combate a essa violência. Revista Signos, Lajeado, v. 37, n. 2, p. 216-234, 2016. Disponível em: <http://www.univates.br/revistas/index.php/signos/article/ view/I I00 >. Acesso em: 08 jan. 2019.

SCOTT, Joan Wallach. Gender as a useful category of historical analysis. In: Culture, society and sexuality. Routledge, 2007. p. 77-97.

UN WOMEN. United Nations Entity for Gender Equality and the Empowerment of Women. Progress of the World's Women 2015-2016: Transforming Economies, Realizing Rights, 2015. Disponível em: <http://www.unwomen.org/-/ media/headquarters/attachments/sections/library/publications/20I5/poww-20I5-20I6-en.pdf?la $=$ en\&vs $=0>$. Acesso em: 03 jan. 2019.

UNHCR. United Nations Refugee Agency. Initial Assessment Report: Protection Risks for Women and Girls in the European Refugee and Migrant Crisis. UNHCR: Genebra, Suíça, 2016.

WEBER, Douglas Luís. Deslocamentos Internacionais, Educação e Saúde Global: Os discursos biopolíticos que produzem o sujeito migrante. 2017. Dissertação de Mestrado (Programa de Pós-Graduação em Educação - Mestrado) - Universidade de Santa Cruz do Sul, Santa Cruz do Sul, 2017.

WEINTRAUB, Ana Cecília Andrade de Moraes; TITTANEGRO, Gláucia Rita; VASCONCELLOS, Maria da Penha. Razões do migrar no contemporâneo. In: FORTES, Paulo; RIBEIRO, Helena. (org). Saúde Global. Barueri: Manole, 2014. 